\title{
Impact of heteroatom addition into mesoporous silica for water adsorption in the low partial pressure range
}

\author{
Jéssica de O. N. Ribeiro ${ }^{1}\left[\right.$ - Débora G. da Silva ${ }^{2} \cdot$ Daniela C. L. Vasconcelos ${ }^{2} \cdot$ Wander L. Vasconcelos $^{2}$
}

Received: 19 October 2020 / Revised: 2 August 2021 / Accepted: 4 August 2021 / Published online: 17 August 2021

( ) The Author(s), under exclusive licence to Springer Science+Business Media, LLC, part of Springer Nature 2021

\begin{abstract}
Mesoporous silicas are known to be high-performing water adsorbents in high humidity levels due to their large pore volumes. However, for low humidity conditions, these materials typically present a less expressive performance, which is a drawback for many applications. In the present report, mesoporous silica SBA-15 was functionalized with $\mathrm{Al}, \mathrm{Ti}, \mathrm{Zr}$ and $\mathrm{Li}$ in order to improve their performance in this condition. The influence of functionalization in porosity, morphology and acidic sites was investigated. Samples with an increased number of acidic sites and with higher microporosity when compared to pure silica were produced. This was responsible for their enhanced performance for water adsorption in low moisture conditions. Sample functionalized with zirconium in SBA-15 synthesis improved the water adsorption capacity of pure silica by three times, reaching up to $127 \mathrm{~g} \mathrm{~kg}^{-1}$ at a relative pressure of 0.2 and $570 \mathrm{~g} \mathrm{~kg}^{-1}$ close to saturation pressure. This sample was found to be a promising material to be applied in processes which require high adsorption capacities in both low and high water partial pressure ranges. Moreover, the understanding of the mechanisms behind the heteroatom functionalization can be applied to any silica material in order to enhance its attractiveness towards any polar molecule.
\end{abstract}

Keywords Mesoporous silica $\cdot$ Heteroatom functionalization $\cdot$ Water adsorption $\cdot$ Co-condensation

\section{Introduction}

The adsorption of water vapor is a process of great relevance due to its wide possibilities of application, such as in chemical and petro-chemical industry, gas and liquid drying, microelectronics, pharmaceuticals, food preservation and processing, architecture materials, cosmetics, paper making, thermal energy conversion and storage, humidity control, adsorption heat pumps, and even fresh water production from the air [1-3]. Therefore, there is a growing interest in the research for novel materials to be applied in this field.

Mesoporous silicas are emerging new materials being investigated for many applications, such as catalysis [4-11], environment [12-15], drug delivery [16-18], production of sensors [19, 20], nanotechnology [21], and others. Among all classes of mesoporous silicas, the so-called SBA-15

Jéssica de O. N. Ribeiro

jessicanotorio@ufla.br

1 Universidade Federal de Lavras, Rua Aquenta Sol, s/n, Lavras, Minas Gerais, Brazil

2 Universidade Federal de Minas Gerais, Av. Pres. Antônio Carlos, 6627, Belo Horizonte, Minas Gerais, Brazil
(Santa Barbara Amorphous 15) has been attracting much attention. They present hexagonally arranged cylindrical mesopores of uniform diameter, and high values of surface area (from 500 to $1000 \mathrm{~m}^{2} \mathrm{~g}^{-1}$ ) and pore volume (which can surpass $1 \mathrm{~cm}^{3} \mathrm{~g}^{-1}$ ). Their pore sizes can be easily controlled by changes in the synthesis parameters, which makes their textural features tailorable for each specific application. Another interesting characteristic of this class of silicas is their relatively thick pore walls, which can range from 3 to $6 \mathrm{~nm}$ [22]. These thick pore walls allied to the 2D hexagonal geometry would enable these materials to have a higher resistance against degradation caused by contact with water (also called hydrothermal resistance) when compared to other classes of silica [23].

The presence of a large volume of mesopores enables these materials to present adsorption capacities up to $1000 \mathrm{~g}$ $\mathrm{kg}^{-1}$ when exposed to high relative humidities [24]. For a low partial pressure range, SBA-15 materials were so far found to present a small adsorption capacity [25] due to their limited attractiveness towards water molecules. Improving the performance of these materials in this range is a requirement for applications such as drying of gaseous streams, rotary desiccant dehumidifiers [3], and adsorption heat 
transformers [25]. This is a challenge which has been so far little explored in the literature [26].

The works of Saliba et al. [27] and Maaz et al. [25] have determined that the volume of micropores present in the structure (the corona of SBA-15 [28]) as well as the density of silanol groups on the surface have an influence on the adsorption capacity in the low partial pressure range. Therefore, their enhancement would favor the performance in this region. Another approach would be the insertion of metallic heteroatoms into the framework of silica. This hypothesis was simulated by Perez-Beltran et al. [29] for substitutions with aluminum and titanium, and experimentally tested by Endo et al. [30] with aluminum and zirconium and Wei et al. [3] with aluminum. They have observed that the insertion of these metals created local distortions in the network of silica, which in turn improved the acidity of silanol groups present on the surface, creating stronger Brønsted and Lewis acid sites. This resulted in improved hydrophilicity and enhanced the low relative pressure performance of these materials. This is thus a promising strategy.

The works cited above were pioneer and exploratory, and there are still many aspects of the impact of heteroatom insertion into mesoporous silica for water adsorption in the low partial pressure range to be explored, such as which is the best metal for insertion. For this study, two groups of samples were synthesized, one using the regular SBA-15 synthesis procedure and another using a solution $\mathrm{pH}$ of 1.5. Four heteroatoms were inserted into SBA-15: $\mathrm{Al}, \mathrm{Ti}, \mathrm{Zr}$ and Li. Samples were characterized using nitrogen adsorption (BET), high resolution scanning microscopy (HR-SEM), energy dispersive X-ray spectroscopy mapping (EDX), Fourier transform infrared spectroscopy (FTIR), pyridine adsorption and water adsorption. The performance of the obtained materials was then related to the features observed in the characterization techniques.

\section{Experimental}

\subsection{Chemicals}

The following reactants were used without further purification: tetraethylorthosilicate (TEOS, 98\% purity, SigmaAldrich); Pluronics P123 (Sigma-Aldrich); hydrochloric acid ( $\mathrm{HCl}, 37 \%$, Sigma-Aldrich); deionized water from a Direct-Q Millipore filter; anhydrous toluene (SigmaAldrich); aluminum tri-sec-butoxide (Al-TSB, 97\% purity, Sigma-Aldrich); titanium isopropoxide (97\% purity, SigmaAldrich); zirconium propoxide (70\% solution in 1-propanol, Sigma-Aldrich); and lithium tert-butoxide (97\%, Sigma-Aldrich).

\subsection{Synthesis of pure silica SBA-15}

The synthesis procedure was based on the work of Zhao et al. [31]. The surfactant Pluronics P123 was dissolved into an acidic solution of deionized water and hydrochloric acid through vigorous stirring at $40{ }^{\circ} \mathrm{C}$. When dissolution was complete, TEOS was added to the mixture. The resulting solution was stirred for $24 \mathrm{~h}$ at $40{ }^{\circ} \mathrm{C}$ (molar ratios 1 TEOS:5.92 HCl:177 $\left.\mathrm{H}_{2} \mathrm{O}: 0.017 \mathrm{P} 123\right)$. The slurry formed was then filtered and the powder collected was dried $\left(100{ }^{\circ} \mathrm{C}\right)$. A heat treatment was executed to remove the surfactant consisted $\left(550{ }^{\circ} \mathrm{C}\right.$ at $1{ }^{\circ} \mathrm{C} \mathrm{min}{ }^{-1}, 6 \mathrm{~h}$ at $550^{\circ} \mathrm{C}$, cooling at $10{ }^{\circ} \mathrm{C} \mathrm{min}^{-1}$. This sample was named "PSi" (Pure Silica).

\subsection{Heteroatom functionalization: co-condensation approach 1}

The first co-condensation approach used for functionalization presents very similar synthesis steps to those used for the pure silica. The difference is that after $1 \mathrm{~h}$ of reaction of TEOS in the acid solution of P123, the metal alkoxide precursor was also added to the mixture (metal/silicon molar ratio of 0.03 ). The $\mathrm{pH}$ of synthesis used was close to 0 . Then the solution was allowed to continue reacting $\left(40{ }^{\circ} \mathrm{C}\right.$ for $24 \mathrm{~h}$ ). The following steps of synthesis were identical to the production of PSi. Samples produced by this method were named C1-Al, C1-Ti, C1-Zr and C1-Li.

\subsection{Heteroatom functionalization: co-condensation approach 2}

In the second approach used for co-condensation, the amount of $\mathrm{HCl}$ was reduced in order to reach a $\mathrm{pH}$ value of 1.5 , following reports from the literature [32-35]. All the other synthesis steps and molar ratios were the same as described for the first co-condensation approach and the pure silica production, except that the solids produced were recovered through centrifugation instead of filtration, due to a more viscous solution formed at the end of the syntheses. Samples produced using this methodology were labeled $\mathrm{C} 2-\mathrm{Al}, \mathrm{C} 2-\mathrm{Ti}, \mathrm{C} 2-\mathrm{Zr}$ and C2-Li.

Materials produced by all approaches, including the sample of pure silica, were subjected to a rehydroxylation procedure to finalize the synthesis in order to recover the hydroxyl groups lost during the heat treatment. This process consisted of dispersing the powders into deionized water and keeping the suspension obtained in static condition $\left(60{ }^{\circ} \mathrm{C}\right.$ for $\left.6 \mathrm{~h}\right)$. After that, the suspension was filtered and the powders were dried and prepared for the characterization techniques. 


\subsection{Characterization and performance evaluation}

Textural characteristics of samples were evaluated through nitrogen adsorption in a Micromeritics ASAP 2020C apparatus [degassing procedure at $250{ }^{\circ} \mathrm{C}$ for $24 \mathrm{~h}$ under vacuum, analysis under liquid nitrogen bath $\left(-196^{\circ} \mathrm{C}\right)$ ]. The BET method was used to calculate the surface area between relative pressures from 0.05 to 0.3 and the NLDFT method (cylindrical pores in silicon oxide model, using the adsorption branch) for the distribution of pore sizes. This Micromeritics equipment was also used to record water adsorption isotherms. The same degassing procedure was used in this case $\left(250{ }^{\circ} \mathrm{C}\right.$ for $24 \mathrm{~h}$ under vacuum). Analyses were conducted in a water bath at $5{ }^{\circ} \mathrm{C}$.

HR-SEM and EDX mapping were performed at a FEI Quanta FEG 3D microscope equipped with a Bruker Nano X-flash 5010 EDS detector. Powders were dispersed onto carbon tape covered stubs and coated with $15 \mathrm{~nm}$ of carbon to improve electron conduction for imaging. A voltage of $5 \mathrm{kV}$ was used for morphology images and $15 \mathrm{kV}$ for chemical composition. EDX maps were processed by EDS SPRIT software from Bruker.

FTIR analyses were conducted in a Perkin Elmer Frontier spectrophotometer using an ATR accessory (range of $1350-850 \mathrm{~cm}^{-1}$, resolution of $2 \mathrm{~cm}^{-1}, 80 \mathrm{scans}$ ). In this spectrophotometer were also recorded spectra of pyridine adsorption/desorption. For this analysis, first samples were degassed at $250{ }^{\circ} \mathrm{C}$ for $1 \mathrm{~h}$ under vacuum and then contacted with pyridine vapors at $60{ }^{\circ} \mathrm{C}$ for $1 \mathrm{~h}$. Next, pyridine was desorbed for $10 \mathrm{~min}$ at $150{ }^{\circ} \mathrm{C}$ and the spectra were collected $\left(1750-850 \mathrm{~cm}^{-1}, 2 \mathrm{~cm}^{-1}\right.$ of resolution and 100 scans). For measurements of peak height and absorbance, the main $\mathrm{Si}-\mathrm{O}-\mathrm{Si}$ peak at $1060 \mathrm{~cm}^{-1}$ was taken as reference to normalize all spectra.

\section{Results and discussion}

\subsection{Characterization of pore structure and morphology}

Nitrogen adsorption was performed in order to bring knowledge about the porosity of samples. Figure 1 shows the nitrogen adsorption isotherms of $\mathrm{C} 1$ samples, synthesized in $\mathrm{pH} \sim 0$. The shape of the isotherms corresponds to type IV (a) of the most recent classification of IUPAC [36], which indicated the presence of cylindrical mesopores of uniform diameter. This information is in agreement with other SBA15 silicas studied in the literature $[18,37]$. They presented surface areas from 714 to $844 \mathrm{~m}^{2} \mathrm{~g}^{-1}$ (Table 1), which were even higher than the sample of pure silica $\left(592 \mathrm{~m}^{2} \mathrm{~g}^{-1}\right)$. This is in accordance with reports from other researchers [38-41]. An important characteristic presented by this group
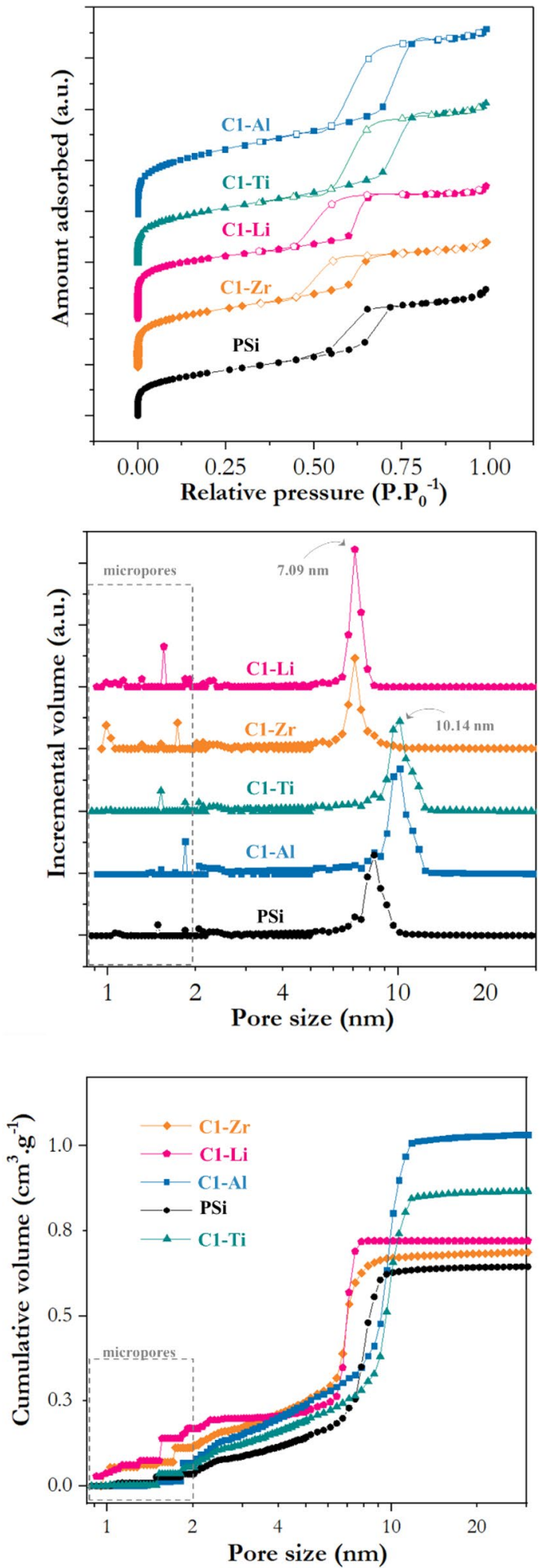

Fig. 1 Nitrogen adsorption isotherms, pore size distributions and cumulative pore volume of samples synthesized with the first co-condensation approach 
Table 1 Textural features of heteroatom functionalized adsorbents and pure silica

\begin{tabular}{lllll}
\hline Sample & $\begin{array}{l}\text { Surface } \\
\text { area }\left(\mathrm{m}^{2}\right. \\
\left.\mathrm{g}^{-1}\right)\end{array}$ & $\begin{array}{l}\text { Micropore } \\
\text { area }\left(\mathrm{m}^{2} \mathrm{~g}^{-1}\right)\end{array}$ & $\begin{array}{l}\text { Pore volume } \\
\left(\mathrm{cm}^{3} \mathrm{~g}^{-1}\right)\end{array}$ & $\begin{array}{l}\text { Micropore } \\
\text { volume }\left(\mathrm{cm}^{3}\right. \\
\left.\mathrm{g}^{-1}\right)\end{array}$ \\
\hline $\mathrm{PSi}$ & 592 & 99 & 0.65 & 0.04 \\
$\mathrm{C} 1-\mathrm{Al}$ & 844 & 154 & 1.04 & 0.07 \\
$\mathrm{C} 1-\mathrm{Ti}$ & 714 & 137 & 0.87 & 0.05 \\
$\mathrm{C} 1-\mathrm{Zr}$ & 757 & 360 & 0.69 & 0.11 \\
$\mathrm{C} 1-\mathrm{Li}$ & 830 & 391 & 0.72 & 0.17 \\
$\mathrm{C} 2-\mathrm{Al}$ & 566 & 394 & 0.50 & 0.13 \\
$\mathrm{C} 2-\mathrm{Ti}$ & 549 & 172 & 0.55 & 0.07 \\
$\mathrm{C} 2-\mathrm{Zr}$ & 504 & 337 & 0.40 & 0.10 \\
$\mathrm{C} 2-\mathrm{Li}$ & 390 & 6 & 0.58 & 0.00 \\
\hline
\end{tabular}

were that the values of micropore surface area and volume displayed average increases of $146 \%$ and $119 \%$, respectively, when compared to pure silica. Charan and Rao [39] also reported that the insertion of heteroatoms by co-condensation may alter the amount of micropores in SBA-15 samples. This would occur because the presence of the metals changes the energy of the surfactant-solution interface, since the metals compete with silica in the $\mathrm{S}^{0} \mathrm{H}^{+} \mathrm{X}^{-} \mathrm{I}^{+}$mechanism $\left(\mathrm{S}^{0} \mathrm{H}^{+}\right.$being the surfactant hydrogen bonded to a hydronium ion, $\mathrm{X}^{-}$the chloride ion and $\mathrm{I}^{+}$the protonated inorganic species) [42]. This way, the results suggest that the presence of the metals studied herein favored a deeper entrapment of the PEO chains of P123, giving rise to a larger micropore content. This might also contribute to the increase in surface area observed for functionalized samples when compared to pure silica.

Observing Fig. 1, it is possible to notice that samples $\mathrm{C} 1-\mathrm{Li}$ and $\mathrm{C} 1-\mathrm{Zr}$ presented the main mesopore size of $7.09 \mathrm{~nm}$, whereas $\mathrm{C} 1-\mathrm{Al}$ and $\mathrm{C} 1-\mathrm{Ti}$ presented a larger pore, of $10.14 \mathrm{~nm}$. These sizes were somewhat different from PSi, which exhibited a main mesopore size of $8.27 \mathrm{~nm}$. This further indicated that the addition of the metal alkoxides into the reaction mixture changed the interaction between the inorganic species and the micelles, as discussed before.

Figure 2 exhibits the isotherms of $\mathrm{C} 2$ samples, produced with the addition of heteroatoms in $\mathrm{pH} 1.5$. The shapes of these curves were somewhat distinct from the samples of the previous group, even though they can still be classified as type IV (a). Samples C2-Ti and C2-Li showed a narrower mesopore size distribution than $\mathrm{C} 2-\mathrm{Al}$ and $\mathrm{C} 2-\mathrm{Zr}$, with pore sizes ranging from 7.09 to $9.6 \mathrm{~nm}$, which is in the same range of pore sizes observed for the other group of samples. These results suggested that the use of $\mathrm{pH} 1.5$ was not favorable to the mesostructure formation with the same uniformity as observed for group $\mathrm{C} 1$ in the synthesis conditions used in this work.
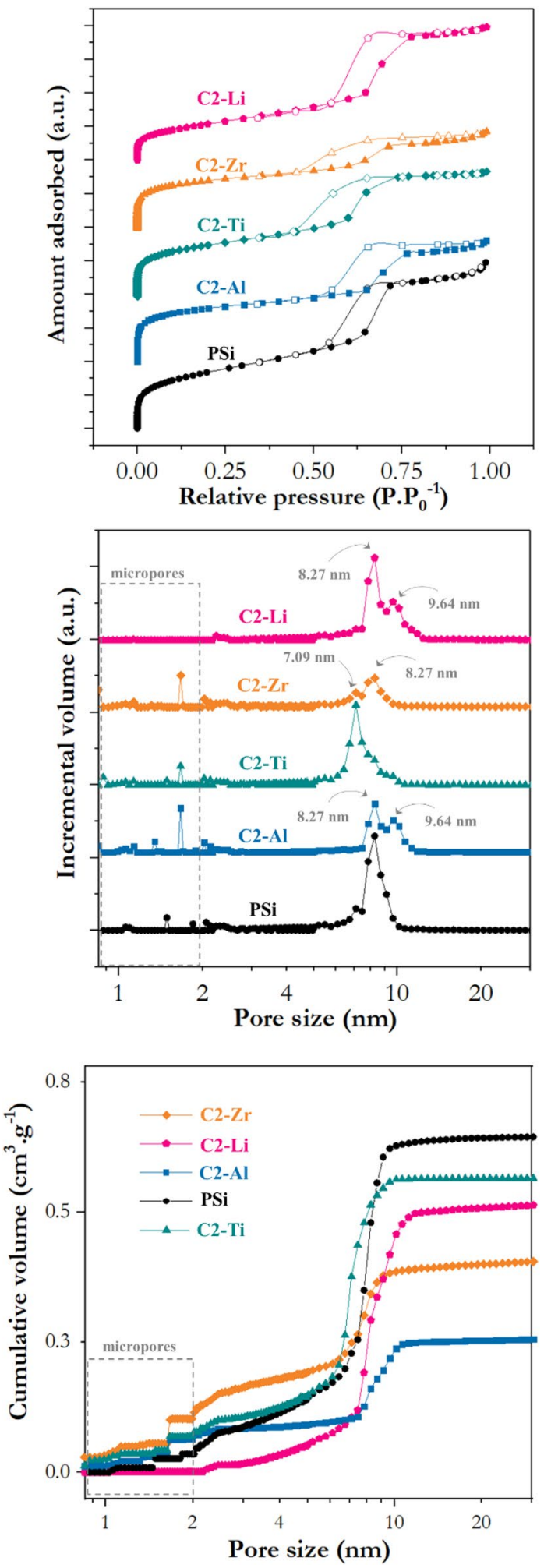

Fig. 2 Nitrogen adsorption isotherms, pore size distributions and cumulative pore volume of samples synthesized with the second cocondensation approach 
Table 1 showed that despite the irregularity in the pore size distribution, samples of group C2 presented significant surface areas $\left(390-566 \mathrm{~m}^{2} \mathrm{~g}^{-1}\right)$. For this group, it was also possible to observe the same increase in the amount of micropores when compared to PSi. The exception in this case was sample $\mathrm{C} 2-\mathrm{Li}$, which presented much smaller values of overall surface area and pore volume as well as the values corresponding to micropores.

HR-SEM micrographs were performed in order to evaluate the morphology of the particles. The first sample observed was PSi, whose images are shown in Fig. 3. In this figure, it was possible to observe a typical morphology of SBA-15 silicas: rod-like particles with hexagonal crosssection [43]. It was also possible to observe the formation of a few spheres, which are also found for this type of material [44].

Images obtained for samples of the $\mathrm{C} 1$ group are given in Fig. 4. The overall aspect of the particles in these samples maintained the rod-like shape of PSi, also with the presence of a few spheres. The main difference observed was the length of the particles chains. Two extreme cases were $\mathrm{C} 1-\mathrm{Zr}$ and $\mathrm{C} 1-\mathrm{Li}$. In $\mathrm{C} 1-\mathrm{Zr}$, short and loose rods with rounded edges were observed. In $\mathrm{C} 1-\mathrm{Li}$, on the other hand, long sequences of fibers were formed by aligned rods, which reached up to $300 \mu \mathrm{m}$ in length. Samples C1-Al and C1-Ti formed intermediary cases, quite similar to PSi.

One hypothesis to explain this difference between the particles sizes lies on the differences in the kinetics of reaction between the alkoxides used in functionalization. The final particle size (or particle chains size) depends on the number of nuclei (seeds) and on the aggregation capability of the surfactant-silica complexes [41], which is also related to the hydrolysis and condensation rates of the sol-gel precursors. If there are many seeds in a sol (fast hydrolysis and slow condensation), particles tend to stay small, as in C1-Zr. If on the other hand there are few nuclei and the rate of condensation overcomes that of hydrolysis (for formation of new nuclei), particles grow and elongate, such as in C1-Li. Once the alkoxides are added to the solution after only $1 \mathrm{~h}$ of reaction of the silica precursor (the reaction mixture is still clear, indicating there were no precipitated particles yet), their addition can be a key point in the nucleation of the particles, and their different nature can lead to the distinct results of morphology observed herein.

In Fig. 5 are given the micrographs of $\mathrm{C} 2$ samples. The morphologies observed in this group are quite distinct from those seen in the previous group. For samples $\mathrm{C} 2-\mathrm{Al}$ and $\mathrm{C} 2-\mathrm{Ti}$, particles became nanodonuts, as Lee and coworkers
Fig. 3 SEM micrographs of PSi sample. Yellow hexagons are merely intended to draw attention to the shape of the cross-section of the particles (Color figure online)

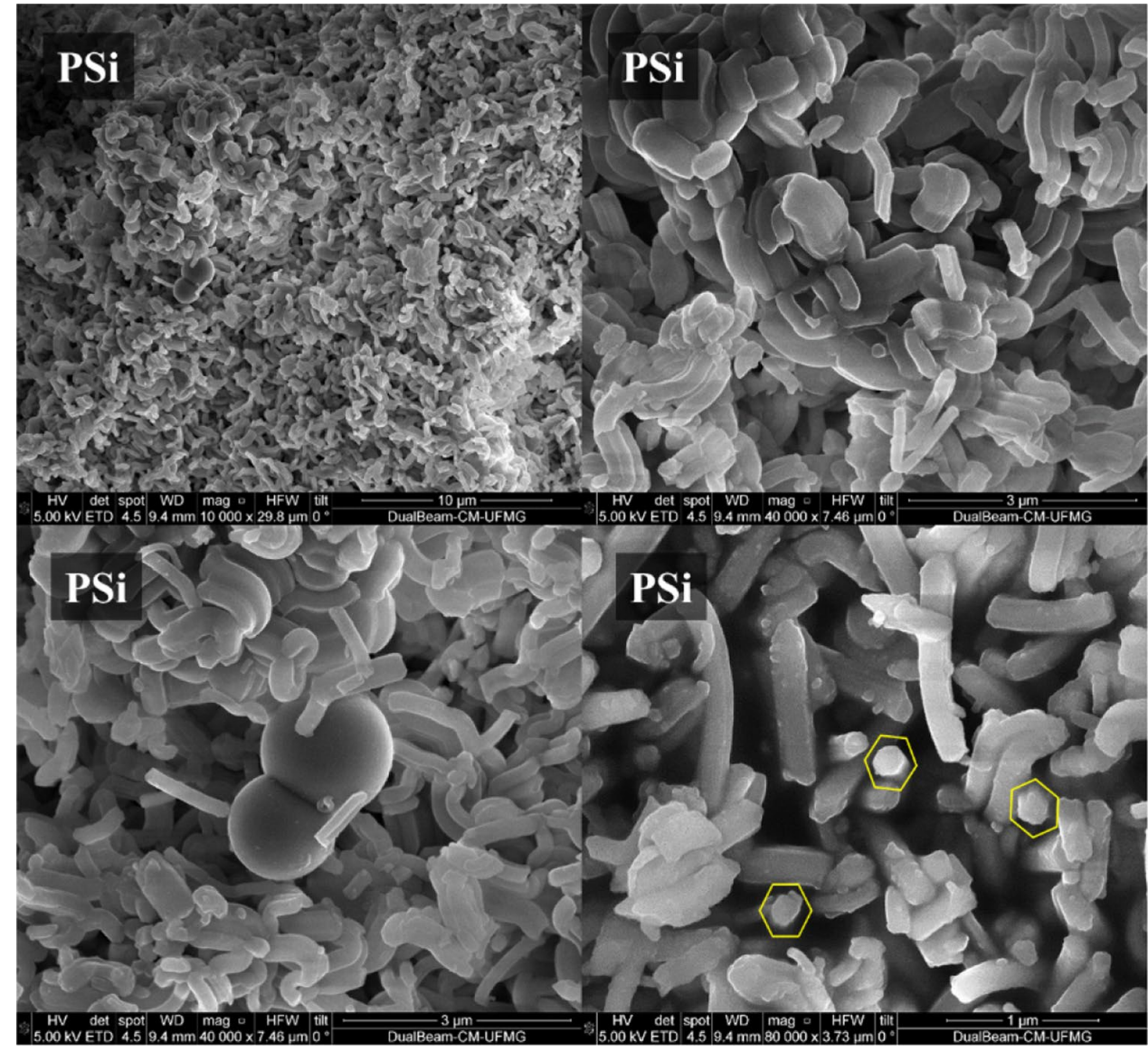


Fig. 4 SEM micrographs of samples functionalized by the first co-condensation approach (C1)

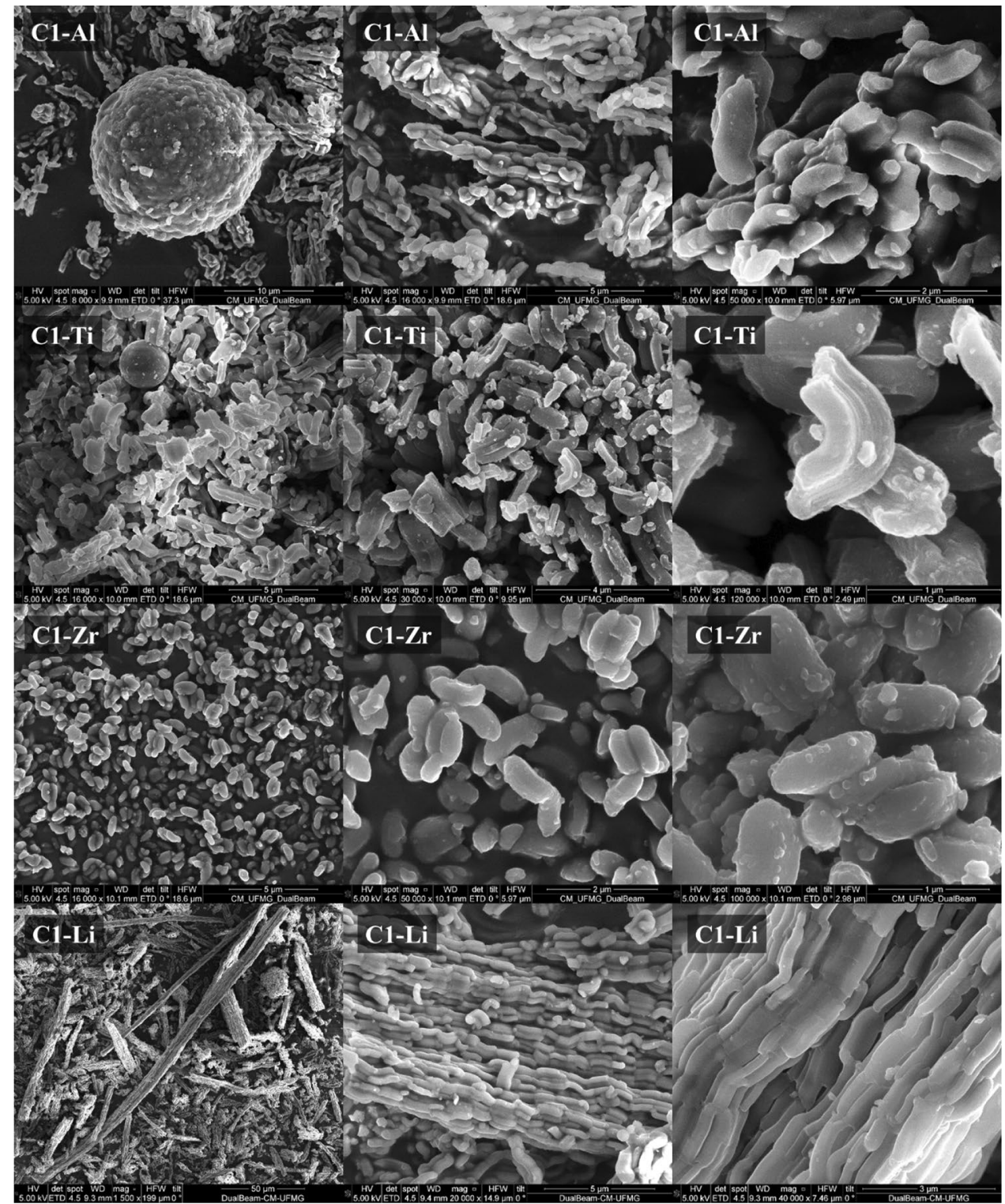

also reported for pure silica SBA-15 [45]. For samples C2-Zr and $\mathrm{C} 2 \mathrm{-Li}$, similar particles were observed, however they were strongly aggregated into large fragments.

It is believed that this difference observed in $\mathrm{C} 1$ and $\mathrm{C} 2$ lies on the distinct $\mathrm{pH}$ of synthesis used in the two cocondensation strategies (close to 0 for $\mathrm{C} 1$ and 1.5 for $\mathrm{C} 2$ ). Kosuge and co-workers have also reported similar effects for samples with reduced amount of $\mathrm{HCl}$ [43]. The use of a different $\mathrm{pH}$ of synthesis also alters the kinetics of hydrolysis and condensation reactions, leading to distinct morphologies for the same reasons as discussed earlier.

\subsection{Characterization of heteroatom insertion}

To initiate the investigation regarding the effectiveness of the insertion of heteroatoms into the framework of silica, EDX mapping was performed. Results of metal content quantification and observations comprising what was observed in the EDX maps are presented in Table 2. Some representative maps are given in Figures S1 and S2 of the Supplementary Material. It is important to remember that lithium-containing samples were not evaluated due to the fact that the metal cannot be observed by this technique.

In general, most samples presented an $\mathrm{M} / \mathrm{Si}$ molar ratio close to that introduced into the synthesis sol (3 mol\%), indicating that the strategies used were well succeeded. The exceptions were $\mathrm{C} 1-\mathrm{Al}$ and $\mathrm{C} 1-\mathrm{Ti}$, which exhibited a smaller percentage of inserted metal. This is in accordance with what was observed by other researchers, such as $\mathrm{Li}$ et al. [41] and Bhange et al. [7]. It is believed that the low insertion of metal in these samples is related to the strongly acidic $\mathrm{pH}$ adopted in the synthesis. In these conditions, most 
Fig. 5 SEM micrographs of samples functionalized by the second co-condensation approach $(\mathrm{C} 2)$
Table 2 Results of quantification of heteroatom addition and observations of EDX mapping

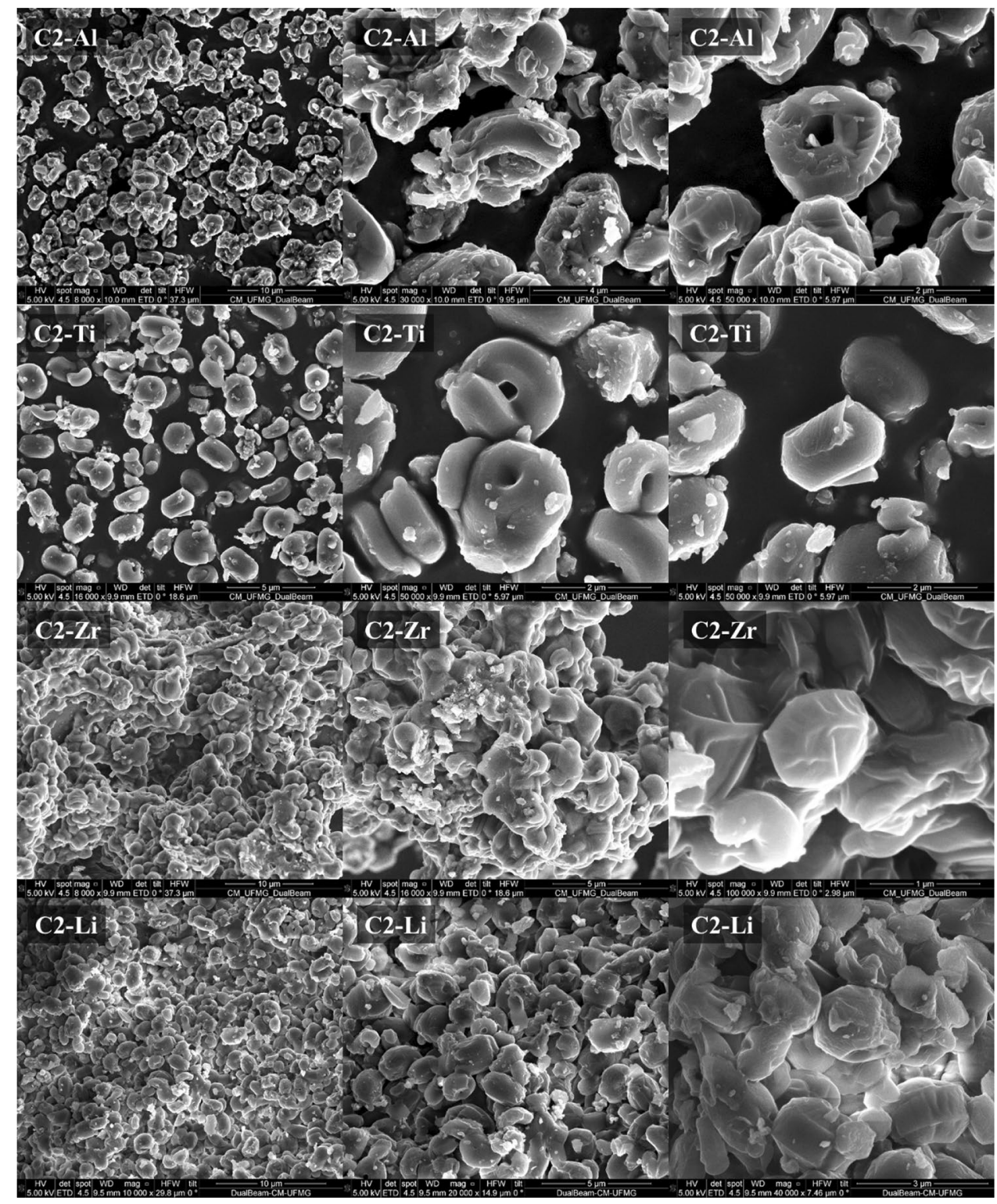

Sample Avg. M/Si Error (\%) Observations $(\mathrm{mol} \%)$

\begin{tabular}{lrrl}
\hline C1-Al & 0.8 & 29 & Homogeneous \\
$\mathrm{C} 1-\mathrm{Ti}$ & $<0.3$ & 26 & Homogeneous. Negligible amount of Ti found in many regions mapped \\
$\mathrm{C} 1-\mathrm{Zr}$ & 3.2 & 5 & Homogeneous \\
$\mathrm{C} 2-\mathrm{Al}$ & 2.9 & 8 & Inhomogeneous: presented regions with up to $11 \mathrm{~mol} \%$ of $\mathrm{Al}$ \\
$\mathrm{C} 2-\mathrm{Ti}$ & 3.5 & 7 & Inhomogeneous: presented regions with up to $41 \mathrm{~mol} \%$ of $\mathrm{Ti}$ \\
$\mathrm{C} 2-\mathrm{Zr}$ & 3.0 & 5 & Inhomogeneous: presented regions with up to $5.6 \mathrm{~mol} \%$ of $\mathrm{Zr}$ \\
\hline
\end{tabular}

of these metals remain as cations in solution, without interacting with silica, and is washed away during filtration. This is proven true as samples of group C2 (synthesized in less acidic conditions) had successful insertions for these heteroatoms. Surprisingly, zirconium was inserted despite the strongly acidic environment $(\mathrm{C} 1-\mathrm{Zr})$. In fact, there has been other reports which could also introduce zirconium using this conventional SBA-15 synthesis method [46, 47].

The homogeneity of the heteroatom insertion was investigated in many regions of the samples through EDX maps. 
It was observed that $\mathrm{C} 1$ samples were homogeneous, despite the small amount of metal present in C1-Al and C1-Ti. C2 samples, however, presented regions of concentration of metal, as registered in Table 2. This suggests the formation of extra-framework oxides.

The investigation regarding the isomorphic substitution of heteroatoms into the framework of silica continued through FTIR analyses. The objective was to observe if there were disturbances in the network of silica caused by the presence of foreign atoms by tracking the $\mathrm{Si}-\mathrm{O}-\mathrm{Si}$ bonds around $1060 \mathrm{~cm}^{-1}[39,48,49]$. The maxima of the peaks associated to these bonds in functionalized samples experienced deviations around the value observed for PSi, which are shown in Fig. 6. The complete spectra are given in Figures S3 and S4 of the Supplementary material. Most of the samples presented a negative shift, i.e. towards smaller wavenumbers. This was also observed by Honda and Hirokawa [50] for several metal insertions. Equation 1 [51] shows that the wavenumber of infrared radiation absorbed in FTIR is related to the force constant of a given bond and to the masses of the atoms involved in this bond.

$v=\frac{1}{2 \pi}\left(\frac{k}{\mu}\right)^{1 / 2}$

where $v$ frequency in $\mathrm{cm}^{-1}, k$ force constant in $\mathrm{N} \mathrm{cm}^{-1}, \mu$ reduced mass in $\mathrm{Kg}$.

The force constant is inversely proportional to the bond length, and can even be used to calculate it from the wavenumber values [52, 53]. Therefore, if the functionalized samples presented the $\mathrm{Si}-\mathrm{O}-\mathrm{Si}$ stretching peak at a smaller wavenumber, it means that $\mathrm{Si}$ and $\mathrm{O}$ atoms were more distant

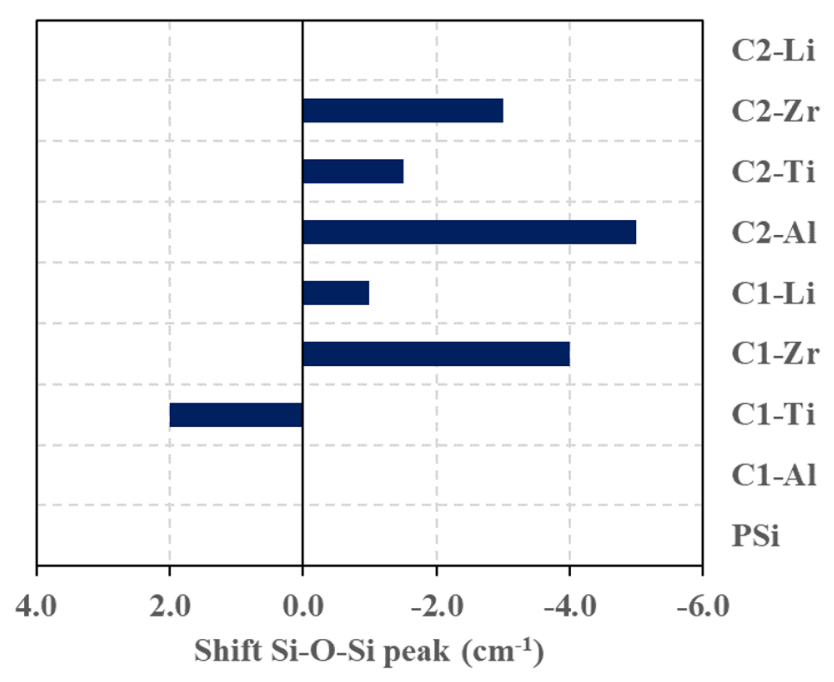

Fig. 6 Bar chart showing the shifts observed in the wavenumbers of the maxima of the Si-O-Si peaks of functionalized samples with respect to $\mathrm{PSi}$ from each other in their framework. This may rise from the substitution of silicon by larger atoms - as it is the case for the metals investigated herein. The ionic radii for the studied metals are: $\mathrm{Si}^{4+}-0.26 \AA, \mathrm{Al}^{3+}-0.39 \AA, \mathrm{Ti}^{4+}-0.42 \AA$, $\mathrm{Li}^{+}-0.59 \AA$, and $\mathrm{Zr}^{4+}-0.59 \AA$ (all for four-fold coordination) [54]. This way, it is possible to relate the negative shifts observed in the FTIR spectra to isomorphic substitutions in the silica framework. It is important to observe that the resolution used in the scans was $2 \mathrm{~cm}^{-1}$, thus only differences above this value present true significance.

For C1 samples, only $\mathrm{C} 1-\mathrm{Zr}$ exhibited a significant negative shift, suggesting the isomorphic substitution of $\mathrm{Zr}$ in the framework. C1-Ti and C1-Al did not present significant shifts, which is in accordance with the EDX results, once they presented a very small amount of metal. C1-Li presented a small negative shift which might suggest a substitution in a low level, though its value is below the resolution of the assay.

In the $\mathrm{C} 2$ group, samples $\mathrm{C} 2-\mathrm{Al}$ and $\mathrm{C} 2-\mathrm{Zr}$ presented very significant negative shifts. Sample C2-Ti presented a smaller value, which agrees with the observations of the EDX mapping. The low isomorphic substitution suggested by this analysis implies on a greater amount of extra-framework oxides, which possibly generated the regions of $\mathrm{Ti}$ concentration observed in the compositional maps. The lithiumadded sample exhibited no shift, suggesting no isomorphic substitution for this material.

\subsection{Characterization of active sites}

Next, pyridine adsorption tests were performed to evaluate the presence of Brønsted and Lewis acid sites. The FTIR spectra of pyridine after desorption at $150{ }^{\circ} \mathrm{C}$ are given in Figs. 7 and 8. In these spectra, peaks at $1447 \mathrm{~cm}^{-1}$ and $1599 \mathrm{~cm}^{-1}$ were clearly identified for most samples. They can be associated to pyridine covalently bonded to Lewis acid sites [55, 56]. For some samples, a peak at $1492 \mathrm{~cm}^{-1}$ was also observed - this peak has been related to adsorption of pyridine in both Lewis and Brønsted acid sites, as a mixed contribution $[57,58]$. In literature it is also mentioned that the presence of Brønsted acid sites is demonstrated by the formation of the pyridinium ion, which produces a characteristic infrared signal at $1540 \mathrm{~cm}^{-1}[59,60]$. Few samples in this study presented visible peaks in this region. This way, it was possible to conclude that, in general, samples investigated herein showed a stronger presence of Lewis-type of acid sites.

Observing Figure 7, it was possible to see that sample PSi exhibited significantly smaller peaks than the functionalized samples, indicating a smaller presence of acid sites. In this figure, sample C1-Li presented well-defined signals at 1599 $\mathrm{cm}^{-1}$ and $1447 \mathrm{~cm}^{-1}$, indicating a well-succeeded functionalization for this sample. This result is in accordance with 


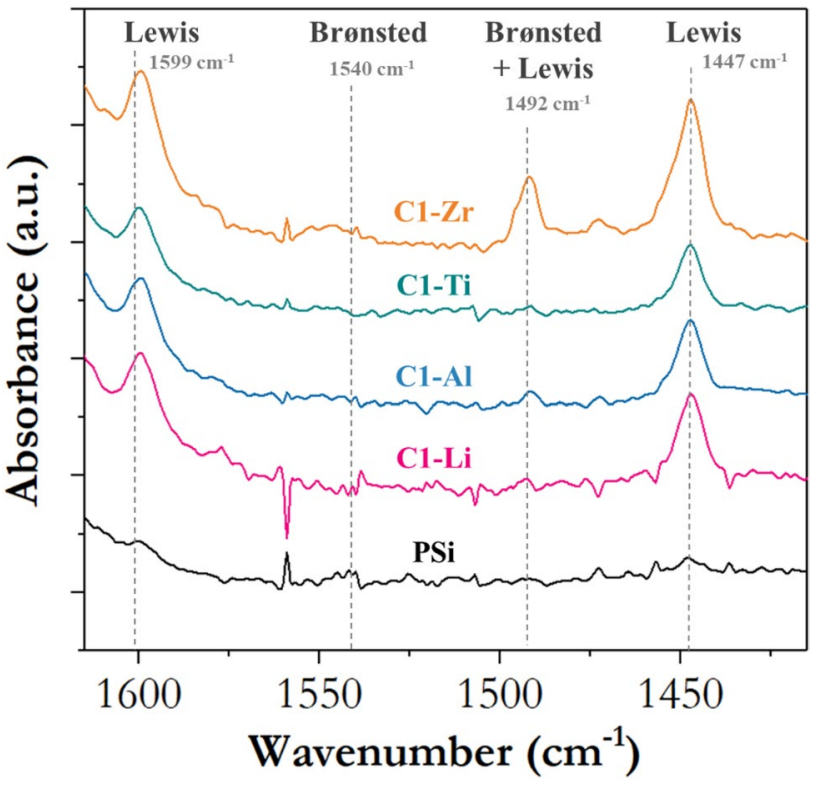

Fig. 7 FTIR spectra of pyridine adsorption after desorption at $150{ }^{\circ} \mathrm{C}$ for samples produced using the first co-condensation approach with the pure silica as reference

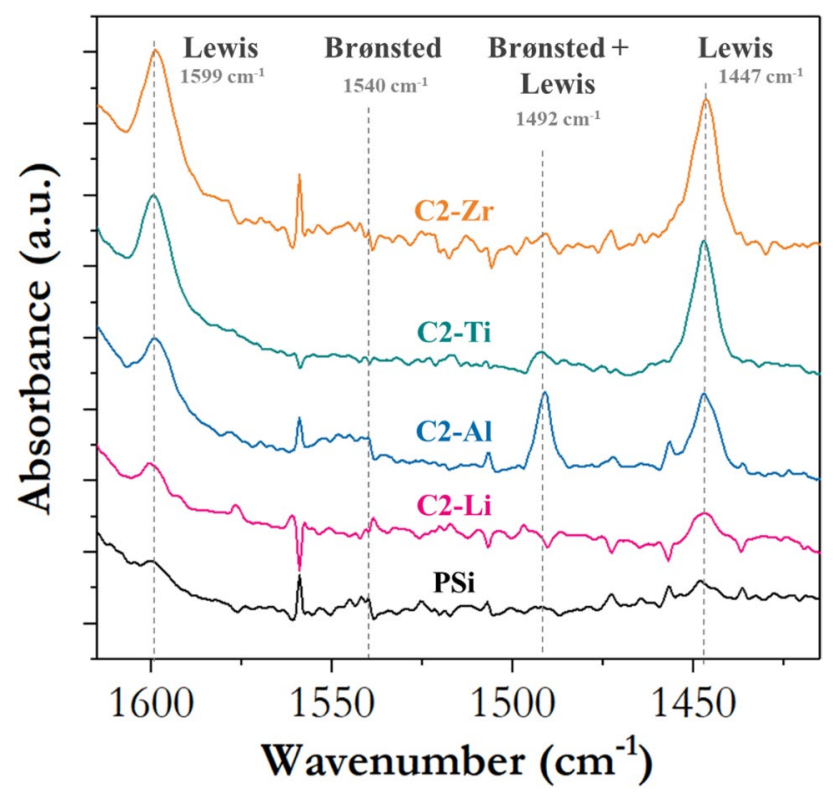

Fig. 8 FTIR spectra of pyridine adsorption after desorption at $150{ }^{\circ} \mathrm{C}$ for samples produced using the second co-condensation approach with the pure silica as reference

the negative shift of the Si-O-Si peak observed in the FTIR spectrum of this sample, discussed earlier. Samples C1-Al and $\mathrm{C} 1-\mathrm{Ti}$ also presented peaks indicating the presence of Lewis $(\mathrm{C} 1-\mathrm{Al}$ and $\mathrm{C} 1-\mathrm{Ti})$ and $\mathrm{Br} \varnothing n s t e d(\mathrm{C} 1-\mathrm{Al})$ acid sites. This allows one to conclude that the small presence of metal observed in the EDX analyses for these samples $(0.8 \mathrm{~mol} \%$ for $\mathrm{C} 1-\mathrm{Al}$ and $0.3 \mathrm{~mol} \%$ for $\mathrm{C} 1-\mathrm{Ti}$ ) was already sufficient to produce more active sites than those originally present in pure silica. Within this group, sample $\mathrm{C} 1-\mathrm{Zr}$ demonstrated the highest peaks for Lewis $\left(1447 \mathrm{~cm}^{-1}\right.$ and $\left.1599 \mathrm{~cm}^{-1}\right)$ and mixed contribution $\left(1492 \mathrm{~cm}^{-1}\right)$ sites, besides a small signal at $1540 \mathrm{~cm}^{-1}$. This means that the functionalization seems to have been the most successful for this sample in the group in terms of the creation of acidic sites. This is coherent with the results of the EDX mapping and FTIR.

As an attempt to compare the overall amount of active sites in the samples, the heights of the peaks at $1447 \mathrm{~cm}^{-1}$ and $1492 \mathrm{~cm}^{-1}$ were measured and added. The peak at $1447 \mathrm{~cm}^{-1}$ was chosen to represent Lewis sites as it usual in literature [60], whereas the peak at $1492 \mathrm{~cm}^{-1}$ was chosen to indirectly represent the contribution of Brønsted sites. This seemed valid since only the samples with distinguishable signals at $1540 \mathrm{~cm}^{-1}$ showed peaks at $1492 \mathrm{~cm}^{-1}$. Since this operation was intended only to be a comparison between the samples in this work and not a quantification of acid sites, it was carried out for all samples. It is going to be proven valuable in future comparisons in this work. The numbers found for this measurement for group $\mathrm{C} 1$ were: 16.92 a.u. for $\mathrm{C} 1-\mathrm{Zr}, 8.84$ a.u. for $\mathrm{C} 1-\mathrm{Li}, 7.18$ a.u. for $\mathrm{C} 1-\mathrm{Al}$ and 6.02 a.u. for C1-Ti.

Regarding samples of group $\mathrm{C} 2$, more evident peaks were observed for $\mathrm{C} 2-\mathrm{Al}, \mathrm{C} 2-\mathrm{Ti}$ and $\mathrm{C} 2-\mathrm{Zr}$, which summed 10.65 a.u., 10.59 a. u. and 11.50 a.u., respectively. These numbers showed that all $\mathrm{C} 2$ samples except $\mathrm{C} 2-\mathrm{Zr}$ showed higher amounts of acid sites when compared to their $\mathrm{C} 1$ analogues.

\subsection{Performance evaluation}

After getting to know the characteristics of the samples, their performance for water adsorption was evaluated. The isotherms collected are given in Figs. 9 and 10. As commented before, the objective of heteroatom insertion in this work was to enhance the adsorption capacity of samples in the low partial pressure range (highlighted in the figures). In general, most of the functionalized samples presented a higher adsorption capacity than pure silica in this region, showing that the overall strategy adopted herein was successful.

Considering group C1 (Fig. 9), significant increases in capacity were obtained. For this group, the increasing order of adsorption capacity observed was $\mathrm{Zr}>\mathrm{Li}>\mathrm{Al}>\mathrm{Ti}$. This is in alignment with the characterization results, which showed a partial insertion of metals for C1-Al and C1-Ti (EDX), with a small formation of active sites (pyridine). This way, it was possible to explain why these samples displayed a smaller capacity than $\mathrm{C} 1-\mathrm{Zr}$ and $\mathrm{C} 1-\mathrm{Li}$, but still higher than PSi. The sample with zirconium addition, on the other hand, exhibited the highest capacity in the group and also among all samples evaluated herein, presenting $127 \mathrm{~g}$ $\mathrm{kg}^{-1}$ of adsorption capacity at 2 mbar. This represents a three-fold increase in the adsorption capacity of pure silica. 


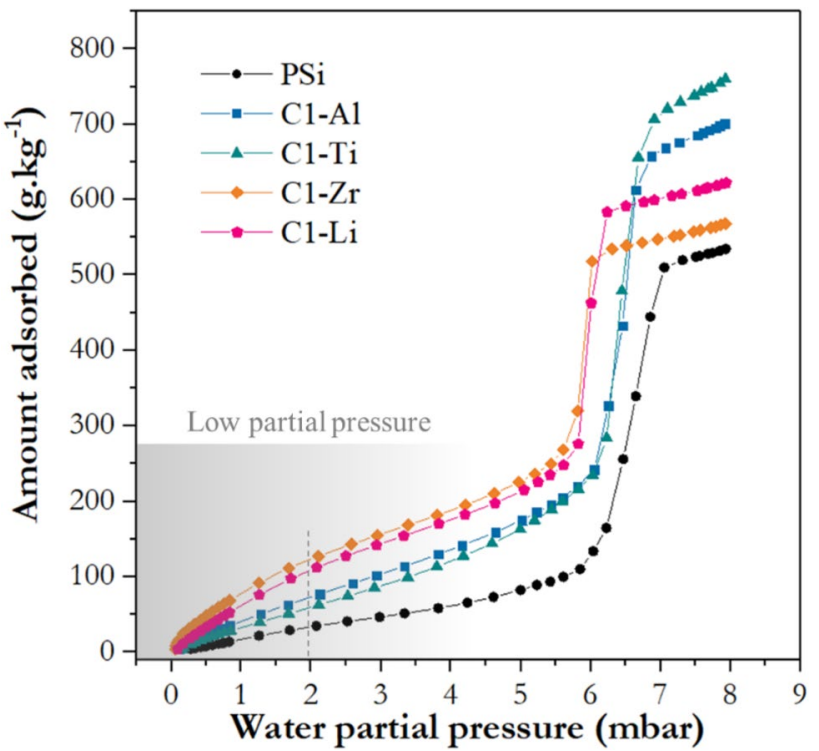

Fig. 9 Water adsorption isotherms at $5{ }^{\circ} \mathrm{C}$ of samples functionalized using the first co-condensation approach with the pure silica sample for comparison. The region considered as low partial pressure in this text is highlighted

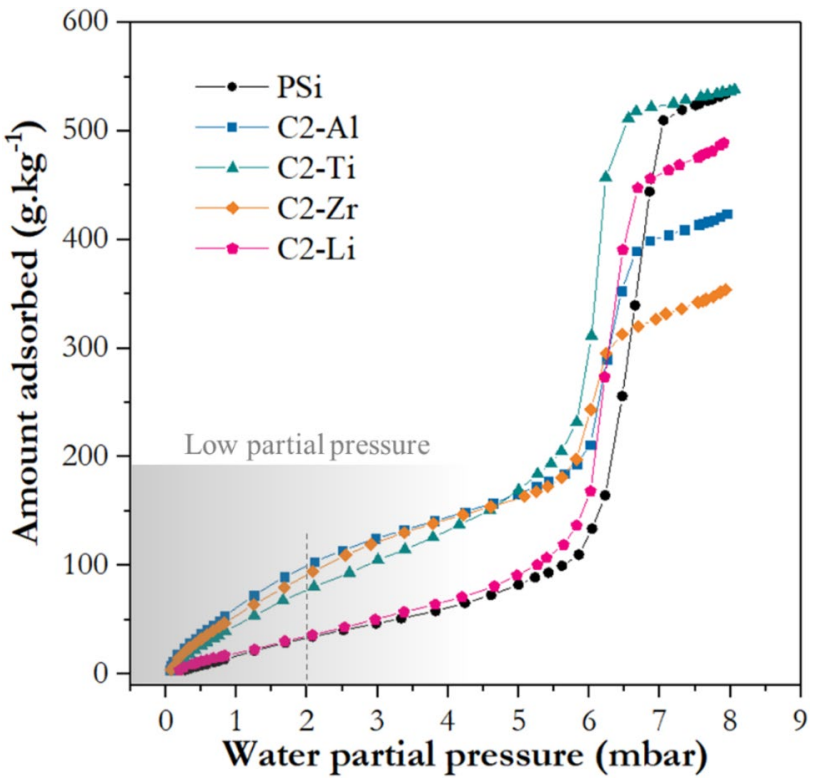

Fig. 10 Water adsorption isotherms at $5{ }^{\circ} \mathrm{C}$ of samples functionalized using the second co-condensation approach with the pure silica sample for comparison. The region considered as low partial pressure in this text is highlighted

Its adsorption capacity in the low partial pressure range was also found to be among the highest in the literature. Comparing within the same relative pressure $\left(\mathrm{P} / \mathrm{P}_{0}=0.2\right)$, it overcame the performance of Al-MCM-41 at $25^{\circ} \mathrm{C}\left(90 \mathrm{~g} \mathrm{~kg}^{-1}\right)$ [61], Al-SBA- 15 at $30{ }^{\circ} \mathrm{C}\left(50 \mathrm{~g} \mathrm{~kg}^{-1}\right)$ [62], Zr-MPS at $25^{\circ} \mathrm{C}$ $\left(90 \mathrm{~g} \mathrm{~kg}^{-1}\right)$ [63] and rehydroxylated MCM- 41 at $25^{\circ} \mathrm{C}(80 \mathrm{~g}$ $\mathrm{kg}^{-1}$ ) [64]. Its capacity was comparable to Al-MCM-41 developed by Chen et al. [1], which presented $130 \mathrm{~g} \mathrm{~kg}^{-1}$ for adsorption at $25^{\circ} \mathrm{C}$. Nevertheless, at $\mathrm{P} / \mathrm{P}_{0}=1$, their material reached $350 \mathrm{~g} \mathrm{~kg}^{-1}$, whereas $\mathrm{C} 1-\mathrm{Zr}$ reached up to $570 \mathrm{~g}$ $\mathrm{kg}^{-1}$. This way, $\mathrm{C} 1-\mathrm{Zr}$ was found to be a promising material to be applied in processes which require high adsorption capacities in both low and high water partial pressure ranges. It is important to highlight that the increase in performance for the low partial pressure range obtained with the approach reported herein does not incur in the sacrifice of the adsorption capacity in high moisture conditions.

Observing now results for group C2 (Fig. 10), C2-Al, $\mathrm{C} 2-\mathrm{Ti}$ and $\mathrm{C} 2-\mathrm{Zr}$ presented a significantly higher adsorption capacity than PSi at 2 mbar, reaching a $203 \%$ increase for C2-Al. C2-Li presented a performance very close to PSi, confirming the indication of the characterization techniques that the functionalization was not well-succeeded for this sample. In general, adsorption capacities of $\mathrm{C} 2$ samples were somewhat smaller than those presented by the $\mathrm{C} 1$ group. Characterization analyses discussed previously showed that C2 samples presented less uniform pore structures than $\mathrm{C} 1$ samples, and also morphologies with twisted and aggregated particles. This may hinder the diffusion and access of water molecules to adsorption sites. In summary, results showed that the use of a solution $\mathrm{pH}$ of 1.5 instead of close to 0 impacted negatively the formation of mesopores and the macrostructure of particles, also favoring the precipitation of metals as extra-framework oxides. However, this was the only strategy capable of quantitatively inserting $\mathrm{Al}$ and $\mathrm{Ti}$ into the structure.

\subsection{Relationship between properties and performance}

As commented previously, it is believed that the micropore volume and the creation of acidic sites enabled by the insertion of metallic heteroatoms into the silica framework are key features for water adsorption capacity in the low partial pressure range [65]. In order to observe the validity of this hypothesis for the set of samples developed in this work, the plot in Fig. 11 was constructed. This figure showed that only samples which associate a high micropore volume with a large amount of acidic sites present the highest adsorption capacities at 2 mbar. This can be explained through the water adsorption mechanism, as proposed by Maheshwari et al. [66] and Grünberg et al. [67]. Initially, water molecules are attracted by adsorption sites on the surface. These groups can be hydroxyl terminations and Lewis or Brønsted acid sites. This already demonstrates the importance of the presence of surface $\mathrm{OH}$ groups and of the creation of acidic sites on the materials. The next water molecules on the surrounding gas can be attracted to other sites available on the surface as well as to already adsorbed water molecules. 
Fig. 11 Relationship between micropore volume, added heights of peaks at $1447 \mathrm{~cm}^{-1}$ and $1492 \mathrm{~cm}^{-1}$ in the pyridine adsorption spectra and water adsorption capacity in the low partial pressure range (2 mbar). Samples with highest adsorption capacity present simultaneously high micropore volume and large amount of acidic sites

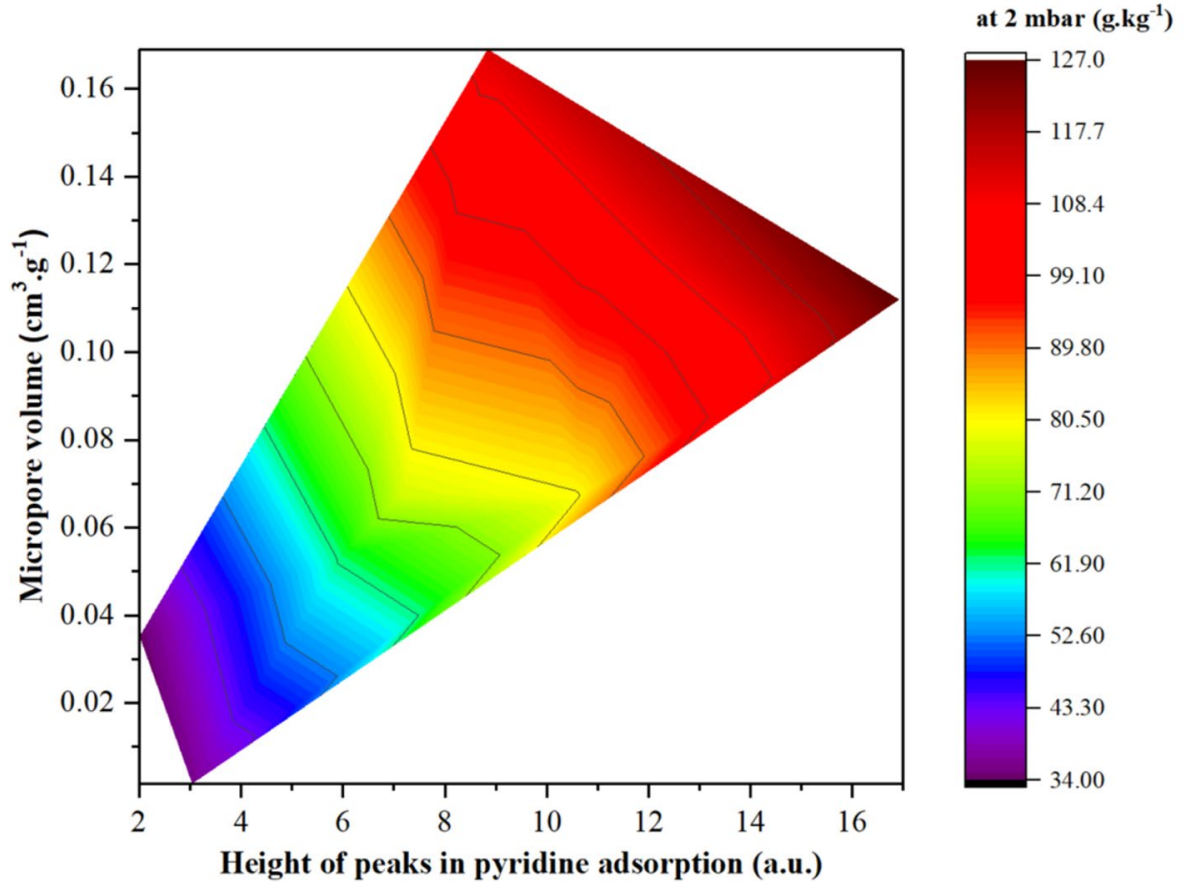

This occurs due to the fact that, unlike other adsorbates, molecule-surface and molecule-molecule interactions are energetically similar for water. From this, results the formation of isles or clusters of water molecules around adsorption sites, which grow as the process carries on. If these clusters are placed inside of micropores as those present in SBA-15, they grow until their entire volume is occupied, in a mechanism known as micropore filling. If instead they are placed on the walls of mesopores and the partial pressure keeps rising, they will continue to grow until two or more of these clusters coalesce, forming a continuous mass of water covering the entire pore diameter. It is in this moment that capillary condensation occurs, leading to the steep increase in the isotherm curves, which can be observed from 5 to $7 \mathrm{mbar}$ in Figs. 9 and 10. This process continues until the entire pore volume is virtually complete, as discussed previously. This way, it is possible to understand how these two properties of the materials relate to their water adsorption capacity in the low partial pressure range.

\section{Conclusions}

This work investigated the relationship between the insertion of heteroatoms into mesoporous silica SBA-15 and the water adsorption in the low partial pressure range by comparing two groups of samples for the addition of $\mathrm{Al}, \mathrm{Ti}, \mathrm{Zr}$ and $\mathrm{Li}: \mathrm{C} 1$, functionalized using the co-condensation method with the regular SBA-15 synthesis procedure; and C2, cocondensed in $\mathrm{pH}=1.5$. It was concluded that method $\mathrm{C} 1$ produced samples with the highest surface areas and was not capable of inserting $\mathrm{Al}$ and Ti. Co-condensation $\mathrm{C} 2$ was able to insert all heteroatoms except lithium and produced samples with smaller surface areas. Investigation regarding morphology showed the different alkoxides and $\mathrm{pHs}$ used in the co-condensation approach impacted the morphologies of the final materials, leading to the formation of rods, fibers and nanodonuts. Pyridine adsorption showed that functionalized samples presented a higher number of active sites than the sample of pure silica, mostly of Lewis type. Sample C1-Zr was found to be a promising material to be applied in processes which require high adsorption capacities in both low and high water partial pressure ranges. This sample showed an adsorption capacity three times higher than pure silica, reaching up to $127 \mathrm{~g} \mathrm{~kg}^{-1}$ at a relative pressure of 0.2 and $570 \mathrm{~g} \mathrm{~kg}^{-1}$ close to saturation pressure. This superior performance was explained due to the fact that this sample associated a high micropore volume with a large amount of acidic sites. It is important to highlight that the increase in performance for the low partial pressure range obtained with the approach reported herein does not incur in the sacrifice of the adsorption capacity in high moisture conditions. Finally, the understanding of the mechanisms behind the functionalization of silica with metallic heteroatoms can be applied to any silica material in order to enhance its attractiveness towards any polar molecule. The knowledge generated herein can thus be widely used by many fields of investigation. 
Supplementary Information The online version contains supplementary material available at https://doi.org/10.1007/s10450-021-00336-6.

Acknowledgements The authors thank the microscopy center of the Federal University of Minas Gerais (UFMG, Brazil) for the microscopy images. The authors also acknowledge the very interesting and useful suggestions provided by the reviewers of this paper. Unfortunately, the additional experimental information required could not be included in the paper due to the COVID-19 pandemic, which hindered our access to laboratories. However, their valuable contributions will be implemented in future works.

\section{Declarations}

Conflict of interest The authors declare no conflict of interest for the work presented.

\section{References}

1. Chen, H., Ding, J., Wang, W., Wei, X., Lu, J.: Water adsorption characteristics of MCM-41 post-modified by Al grafting and cations doping: equilibrium and kinetics study. Adsorption 23, 113-120 (2017). https://doi.org/10.1007/s10450-016-9829-2

2. Puzyrev, I.S., Sobina, E.P., Adamova, L.V., Kodess, M.I., Medvedevskikh, S.V.: Template synthesis and water vapor adsorption by micro- and mesoporous silica gels with high specific surface area. Glass Phys. Chem. 41, 187-193 (2015). https://doi.org/10. 1134/S1087659615020108

3. Wei, X., Wang, W., Xiao, J., Zhang, L., Chen, H., Ding, J.: Hierarchically porous aluminosilicates as the water vapor adsorbents for dehumidification. Chem. Eng. J. 228, 1133-1139 (2013). https:// doi.org/10.1016/j.cej.2013.05.062

4. Bérubé, F., Khadhraoui, A., Janicke, M.T., Kleitz, F., Kaliaguine, S.: Optimizing silica synthesis for the preparation of mesoporous Ti-SBA-15 epoxidation catalysts. Ind. Eng. Chem. Res. 49, 69776985 (2010). https://doi.org/10.1021/ie901659k

5. Bérubé, F., Khadraoui, A., Florek, J., Kaliaguine, S., Kleitz, F.: A generalized method toward high dispersion of transition metals in large pore mesoporous metal oxide/silica hybrids. J. Colloid Interface Sci. 449, 102-114 (2014). https://doi.org/10.1016/j.jcis. 2014.12.001

6. Bérubé, F., Kleitz, F., Kaliaguine, S.: Surface properties and epoxidation catalytic activity of Ti-SBA15 prepared by direct synthesis. J. Mater. Sci. 44, 6727-6735 (2009)

7. Bhange, P., Bhange, D.S., Pradhan, S., Ramaswamy, V.: Direct synthesis of well-ordered mesoporous Al-SBA-15 and its correlation with the catalytic activity. Appl. Catal. A 400, 176-184 (2011). https://doi.org/10.1016/j.apcata.2011.04.031

8. Degirmenci, V., Uner, D., Cinlar, B., Shanks, B.H., Yilmaz, A., Van Santen, R.A., Hensen, E.J.M.: Sulfated zirconia modified SBA-15 catalysts for cellobiose hydrolysis. Catal. Lett. 141, 33-42 (2011). https://doi.org/10.1007/s10562-010-0466-1

9. Du, Y., Liu, S., Zhang, Y., Nawaz, F., Ji, Y., Xiao, F.S.: Ureaassisted synthesis of hydrothermally stable Zr-SBA-15 and catalytic properties over their sulfated samples. Microporous Mesoporous Mater. 121, 185-193 (2009). https://doi.org/10. 1016/j.micromeso.2009.01.030

10. Mutlu, V.N., Yilmaz, S.: Esterification of cetyl alcohol with palmitic acid over $\mathrm{WO}_{3} / \mathrm{Zr}-\mathrm{SBA}-15$ and Zr-SBA-15 catalysts. Appl. Catal. A 522, 194-200 (2016). https://doi.org/10.1016/j.apcata. 2016.05.010

11. Zakharova, M.V., Kleitz, F., Fontaine, F.G.: Lewis acidity quantification and catalytic activity of $\mathrm{Ti}, \mathrm{Zr}$ and $\mathrm{Al}$-supported mesoporous silica. Dalton Trans. 46, 3864-3876 (2017). https:// doi.org/10.1039/C7DT00035A

12. Dana, E., Sayari, A.: Adsorption of heavy metals on amine-functionalized SBA-15 prepared by co-condensation: applications to real water samples. Desalination 285, 62-67 (2012). https://doi. org/10.1016/j.desal.2011.09.034

13. Jang, H.T., Park, Y., Ko, Y.S., Lee, J.Y., Margandan, B.: Highly siliceous MCM-48 from rice husk ash for $\mathrm{CO}_{2}$ adsorption. Int. J. Greenh. Gas Control 3, 545-549 (2009). https://doi.org/10.1016/j. ijggc.2009.02.008

14. Kishor, R., Ghoshal, A.K.: APTES grafted ordered mesoporous silica KIT-6 for $\mathrm{CO}_{2}$ adsorption. Chem. Eng. J. 262, 882-890 (2015). https://doi.org/10.1016/j.cej.2014.10.039

15. Zelenák, V., Badanicová, M., Halamová, D., Cejka, J., Zukal, A., Murafa, N., Goerigk, G.: Amine-modified ordered mesoporous silica: effect of pore size on carbon dioxide capture. Chem. Eng. J. 144, 336-342 (2008). https://doi.org/10.1016/j.cej.2008.07.025

16. Bahrami, Z., Badiei, A., Atyabi, F.: Surface functionalization of SBA-15 nanorods for anticancer drug delivery. Chem. Eng. Res. Des. 2, 1296-1303 (2013)

17. Porta, F.: Mesoporous silica nanoparticles as drug delivery systems (2012). https://books.google.nl/books?id=Au48MwEACA AJ. Accessed 04 Aug 2020

18. Wan, M.M., Sun, X.D., Liu, S., Ma, J., Zhu, J.H.: Versatile drug releaser derived from the Ti-substituted mesoporous silica SBA15. Microporous Mesoporous Mater. 199, 40-49 (2014). https:// doi.org/10.1016/j.micromeso.2014.08.005

19. Melde, B.J., Johnson, B.J., Charles, P.T.: Mesoporous silicate materials in sensing. Sensors (Basel) 8, 5202-5228 (2008). https:// doi.org/10.3390/s8085202

20. Zhang, T., Wang, R., Geng, W., Li, X., Qi, Q., He, Y., Wang, S.: Study on humidity sensing properties based on composite materials of Li-doped mesoporous silica A-SBA-15. Sens Actuators B 128, 482-487 (2008). https://doi.org/10.1016/j.snb.2007.07.012

21. Adhyapak, P.V., Karandikar, P., Vijayamohanan, K., Athawale, A.A., Chandwadkar, A.J.: Synthesis of silver nanowires inside mesoporous MCM-41 host. Mater. Lett. 58, 1168-1171 (2004). https://doi.org/10.1016/J.MATLET.2003.09.008

22. Zhao, D., Feng, J., Huo, Q., Melosh, N., Fredrickson, G.H., Chmelka, B.F., Stucky, G.D.: Triblock copolymer syntheses of mesoporous silica with periodic 50 to 300 angstrom pores. Science 279, 548-552 (1998a). https://doi.org/10.1126/science.279. 5350.548

23. Cassiers, K., Linssen, T., Mathieu, M., Benjelloun, M., Schrijnemakers, K., Van Der Voort, P., Cool, P., Vansant, E.F.: A detailed study of thermal, hydrothermal, and mechanical stabilities of a wide range of surfactant assembled mesoporous silicas. Chem. Mater. 14, 2317-2324 (2002). https://doi.org/10.1021/cm0112892

24. Ribeiro, J.O.N., Vasconcelos, D.C.L., Vasconcelos, W.L.: Importance of the order of addition of the alumina precursor and its type into Al-SBA-15 mesoporous materials for use as water adsorbents. Mater. Res. 22, 1-8 (2019)

25. Maaz, S., Rose, M., Palkovits, R.: Systematic investigation of the pore structure and surface properties of SBA-15 by water vapor physisorption. Microporous Mesoporous Mater. 220, 183-187 (2016). https://doi.org/10.1016/j.micromeso.2015.09.005

26. de O. N. Ribeiro, J., da Silva Daniela, D.G., Vasconcelos, C.L., Vasconcelos, W.L.: Influence of functionalization method on isomorphic substitution and formation of extra-framework oxides in silica for water vapor adsorption. Adsorption. https://doi.org/10. 1007/s10450-021-00335-7

27. Saliba, S., Ruch, P., Volksen, W., Magbitang, T.P., Dubois, G., Michel, B.: Combined influence of pore size distribution and surface hydrophilicity on the water adsorption characteristics of micro- and mesoporous silica. Microporous Mesoporous Mater. 
226, 221-228 (2016). https://doi.org/10.1016/j.micromeso.2015. 12.029

28. Galarneau, A., Cambon, H., Di Renzo, F., Ryoo, R., Choi, M., Fajula, F.: Microporosity and connections between pores in SBA15 mesostructured silicas as a function of the temperature of synthesis. New J. Chem. 27, 73-79 (2002). https://doi.org/10.1039/ b207378c

29. Perez-Beltran, S., Balbuena, P.B., Ramírez-Caballero, G.E.: Surface structure and acidity properties of mesoporous silica SBA-15 modified with aluminum and titanium: first-principles calculations. J. Phys. Chem. C 120, 18105-18114 (2016). https://doi.org/ 10.1021/acs.jpcc.6b05630

30. Endo, A., Inagi, Y., Fujisaki, S., Yamamoto, T., Ohmori, T., Nakaiwa, M.: Synthesis of metal-doped mesoporous silica by spray drying and their adsorption properties of water vapor. Stud. Surf. Sci. Catal. 1, 157-160 (2007)

31. Zhao, D., Feng, J., Huo, Q., Melosh, N., Fredrickson, G.H., Chmelka, B.F., Stucky, G.D.: Triblock copolymer syntheses of mesoporous silica with periodic 50 to 300 angstrom pores. Science 279, 548-552 (1998b)

32. Chorfa, N., Hamoudi, S., Belkacemi, K.: Conjugated linoleic acid formation via heterogeneous hydrogenation/isomerization of safflower oil over mesostructured catalysts. Appl. Catal. A 387, 75-86 (2010). https://doi.org/10.1016/j.apcata.2010.08.006

33. Gracia, M.D., Balu, A.M., Campelo, J.M., Luque, R., Marinas, J.M., Romero, A.A.: Evidences of the in situ generation of highly active Lewis acid species on Zr-SBA-15. Appl. Catal. A 371, 85-91 (2009). https://doi.org/10.1016/j.apcata.2009.09.033

34. Li, Y., Zhang, W., Zhang, L., Yang, Q., Wei, Z., Feng, Z., Li, C.: Direct synthesis of Al-SBA-15 mesoporous materials via hydrolysis-controlled approach. J. Phys. Chem. B 108, 9739-9744 (2004). https://doi.org/10.1021/jp049824j

35. Xing, S., Lv, P., Fu, J., Wang, J., Fan, P., Yang, L., Yuan, Z.: Direct synthesis and characterization of pore-broadened Al-SBA-15. Microporous Mesoporous Mater. 239, 316-327 (2017). https:// doi.org/10.1016/j.micromeso.2016.10.018

36. Thommes, M., Kaneko, K., Neimark, A.V., Olivier, J.P., Rodriguez-reinoso, F., Rouquerol, J., Sing, K.S.W.: Physisorption of gases, with special reference to the evaluation of surface area and pore size distribution (IUPAC technical report ). Pure Appl. Chem. 87, 1051-1069 (2015). https://doi.org/10.1515/ pac-2014-1117

37. Zhao, A., Samanta, A., Sarkar, P., Gupta, R.: Carbon dioxide adsorption on amine-impregnated mesoporous SBA-15 sorbents: experimental and kinetics study. Ind. Eng. Chem. Res. 52, 64806491 (2013). https://doi.org/10.1021/ie3030533

38. Ahmed, K., Rehman, F., Pires, C.T.G.V.M.T., Rahim, A., Santos, A.L., Airoldi, C.: Aluminum doped mesoporous silica SBA-15 for the removal of remazol yellow dye from water. Microporous Mesoporous Mater. 236, 167-175 (2016). https://doi.org/10. 1016/j.micromeso.2016.08.040

39. Charan, P.H.K., Rao, G.R.: Textural and morphological studies of transition metal doped SBA-15 by co-condensation method. J. Chem. Sci. 127, 909-919 (2015). https://doi.org/10.1007/ s12039-015-0847-5

40. van Grieken, R., Escola, J.M., Moreno, J., Rodríguez, R.: Direct synthesis of mesoporous M-SBA-15 (M = Al, Fe, B, Cr) and application to 1-hexene oligomerization. Chem. Eng. J. 155, 442-450 (2009). https://doi.org/10.1016/j.cej.2009.07.016

41. Li, W., Huang, S.J., Liu, S.B., Coppens, M.O.: Influence of the Al source and synthesis of ordered Al-SBA-15 hexagonal particles with nanostairs and terraces. Langmuir 21, 2078-2085 (2005). https://doi.org/10.1021/la047523v

42. Huirache-Acuña, R., Nava, R., Peza-Ledesma, C., Lara-Romero, J., Alonso-Núez, G., Pawelec, B., Rivera-Muñoz, E.: SBA-15 mesoporous silica as catalytic support for hydrodesulfurization catalysts-review. Materials (Basel). 6, 4139-4167 (2013). https://doi.org/10.3390/ma6094139

43. Kosuge, K., Sato, T., Kikukawa, N., Takemori, M.: Morphological control of rod- and fiberlike SBA-15 type mesoporous silica using water-soluble sodium silicate. Chem. Mater. 16, 899-905 (2004). https://doi.org/10.1021/cm030622u

44. Vinoba, M., Bhagiyalakshmi, M., Kwan, S., Ii, Y., Chan, S.: Immobilization of carbonic anhydrase on spherical SBA-15 for hydration and sequestration of $\mathrm{CO}_{2}$. Colloids Surf. B 90, 91-96 (2012). https://doi.org/10.1016/j.colsurfb.2011.10.001

45. Lee, H.I., Kim, J.H., Stucky, G.D., Shi, Y., Pak, C., Kim, J.M.: Morphology-selective synthesis of mesoporous SBA-15 particles over micrometer, submicrometer and nanometer scales. J. Mater. Chem. 20, 8483-8487 (2010). https://doi.org/10.1039/c0jm00820f

46. Tao, C., Li, J., Zhang, Y., Liew, K.Y.: Effect of isomorphic substitution of zirconium on mesoporous silica as support for cobalt Fischer-Tropsch synthesis catalysts. J. Mol. Catal. A 331, 50-57 (2010). https://doi.org/10.1016/j.molcata.2010.08.002

47. Yang, L., Yang, X., Tian, E., Vattipalli, V., Fan, W., Lin, H.: Mechanistic insights into the production of methyl lactate by catalytic conversion of carbohydrates on mesoporous Zr-SBA-15. J. Catal. 333, 207-216 (2016). https://doi.org/10.1016/j.jcat.2015. 10.013

48. Launer, P.J., Arkles, B.: Infrared analysis of organosilicon compounds: spectra-structure correlations. In: Gelest, I. (ed.) Silicon compounds: silanes \& silicones, pp. 175-178. Gelest Inc., Morrisville (2013)

49. Rubio, F., Rubio, J., Oteo, J.L.: A FTIR study of the hydrolysis of tetraethyorthosilicate (TEOS). Spectrosc. Lett. 31, 199-219 (1998)

50. Honda, F., Hirokawa, K., Kajitjra, T.: The infrared spectroscopic study of metals intruded into a silica framework. Spectrochim. Acta A 28, 1793-1803 (1972). https://doi.org/10.1016/05848539(72)80150-8

51. Stuart, B.H.: Infrared spectroscopy: fundamentals and applications. Wiley, Hoboken (2004)

52. Gillespie, R.J., Robinson, E.A.: Characteristic vibrational frequencies of compounds containing Si-O-Si, P-O-P, S-O-S, and Cl-O-Cl bridging groups. Can. J. Chem. 42, 2496-2503 (1964)

53. Singh, H., Yadav, K.L.: Structural, dielectric, vibrational and magnetic properties of $\mathrm{Sm}$ doped $\mathrm{BiFeO}_{3}$ multiferroic ceramics prepared by a rapid liquid phase sintering method. Ceram. Int. 41, 9285-9295 (2015)

54. Lide, D.R.: CRC handbook of chemistry and physics, p. 3485. CRC Press, Boca Raton (2003)

55. Jiang, Y., Geng, T., Li, Q.: Synthesis of stearic acid triethanolamine ester over Al-SBA-15. J. Porous Mater. 19, 369-374 (2012). https://doi.org/10.1007/s10934-011-9483-8

56. On, D.T., Kaliaguine, S.: Ultrastable and highly acidic, zeolitecoated mesoporous aluminosilicates. Angew. Chem. - Int. Ed. 41, 1036-1040 (2002). https://doi.org/10.1002/1521-3773(20020315) 41:6\%3c1036::AID-ANIE1036\%3e3.0.CO;2-R

57. Parry, E.P.: An infrared study of pyridine adsorbed characterization of surface. J. Catal. 2, 371-379 (1963)

58. Wei, Y., Li, Y., Tan, Y., Zhou, J., Wu, Z., Liu, Y.: A facile route for one-pot synthesis of short-channeled bimetallic $\mathrm{Zr}-\mathrm{Al}-\mathrm{SBA}-$ 15. Mater. Lett. 141, 145-148 (2015). https://doi.org/10.1016/j. matlet.2014.11.066

59. Martín, C., Martín, I., del Moral, C., Rives, V.: FT-IR assessment through pyridine adsorption of the surface acidity of alkali-doped $\mathrm{MoO}_{3} / \mathrm{TiO}_{2}$. J. Catal. 146, 415-421 (1994)

60. Moschetta, E.G., Brunelli, N.A., Jones, C.W.: Reaction-dependent heteroatom modification of acid-base catalytic cooperativity in aminosilica materials. Appl. Catal. A 504, 429-439 (2015). https://doi.org/10.1016/j.apcata.2014.10.061 
61. Russo, P.A., Ribeiro Carrott, M.M.L., Padre-Eterno, A., Carrott, P.J.M., Ravikovitch, P.I., Neimark, A.V.: Interaction of water vapour at $298 \mathrm{~K}$ with Al-MCM-41 materials synthesised at room temperature. Microporous Mesoporous Mater. 103, 82-93 (2007). https://doi.org/10.1016/j.micromeso.2007.01.032

62. Talha, Z., Bachir, C., Ziri, S., Bellahouel, S., Bengueddach, A., Villièras, F., Pelletier, M.: Al-rich ordered mesoporous silica SBA-15 materials: synthesis, surface characterization and acid properties fatty acid R'. Catal. Lett. 147, 2116-2126 (2017). https://doi.org/10.1007/s10562-017-2103-8

63. Endo, A., Yamaura, T., Yamashita, K., Matsuoka, F., Hihara, E., Daiguji, H.: Water adsorption-desorption behavior of two-dimensional hexagonal mesoporous silica around freezing point. J. Phys. Chem. C 367, 409-414 (2012). https://doi.org/10.1021/jp309031t

64. Naono, H., Hakuman, M., Tanaka, T., Tamura, N., Nakai, K.: Porous texture and surface character of dehydroxylated and rehydroxylated MCM-41 mesoporous silicas-analysis of adsorption isotherms of nitrogen gas and water vapor. J. Colloid Interface Sci. 225, 411-420 (2000). https://doi.org/10.1006/jcis.2000.6777

65. Ribeiro, J.O.N., Athayde, D.D., Vasconcelos, D.C.L., Vasconcelos, W.L.: Evaluation of surface energetics of zirconium-containing mesoporous silica using novel universal isotherm model. Adsorption 26, 607-618 (2020). https://doi.org/ 10.1007/s10450-020-00229-0

66. Maheshwari, P., Gorgol, M., Kierys, A., Zaleski, R.: Positron probing of liquid-free volume to investigate adsorption-desorption behavior of water in two-dimensional mesoporous SBA-3. J. Phys. Chem. C 121, 17251-17262 (2017). https://doi.org/10.1021/ acs.jpcc. 7 b04317

67. Grünberg, B., Emmler, T., Gedat, E., Shenderovich, I., Findenegg, G.H., Limbach, H.H., Buntkowsky, G.: Hydrogen bonding of water confined in mesoporous silica MCM-41 and SBA-15 studied by $1 \mathrm{H}$ solid-state NMR. Chem. A 10, 5689-5696 (2004). https:// doi.org/10.1002/chem.200400351

Publisher's Note Springer Nature remains neutral with regard to jurisdictional claims in published maps and institutional affiliations. 